\title{
Fuzzy-Logic-Based Direct Torque Control Research On Permanent Magnet Synchronous Motor
}

\author{
Feng Yang \\ School of Automation \\ UESTC \\ Chengdu, China \\ fyang@uestc.edu.cn
}

\author{
Qingwang Song \\ School of Automation \\ UESTC \\ Chengdu, China \\ Sqw4317@126.com
}

\author{
Lei Wang \\ School of Energy Science and \\ Engineering \\ UESTC \\ Chengdu, China
}

\author{
YongDuan Song \\ School of Energy Science \\ and Engineering \\ UESTC \\ Chengdu, China
}

\author{
Shengshan Li \\ School of Automation \\ UESTC \\ Chengdu, China
}

\author{
Yuxing Wang \\ Mengcun County Science \\ and Technology Bureau \\ Cangzhou, China
}

\author{
Yu Zeng \\ School of Energy Science \\ and Engineering \\ UESTC \\ Chengdu, China
}

\begin{abstract}
The basic direct torque control (DTC) scheme may cause big ripples in torque, flux and current because of the small number of applicable voltage vectors. And the variation of the stator resistance has great influence on torque and stator flux estimation especially when the PMSM(permanent magnet synchronous motor) run in a low speed. Several methods are proposed to solve the problems above in this paper. First a SVMDTC (DTC using SVPWM) method is used which decreases the torque and flux ripple considerably. Second a fuzzy stator resistance compensator is introduced to overcome the mismatch between the stator resistance in control algorithm and the actual stator resistance.
\end{abstract}

Keywords- direct torque control ; PMSM; torque; flux- linkage; Fuzzy-Logic

\section{INTRODUCTION}

Permanent magnet synchronous motors (PMSM) are widely used in industrial and robotic applications due to its remarkable features of simple structure, reliable performance, high torque/weight ration and low-consumption [1].Today, the most commonly used methods for controlling PMSM are Field Oriented Control (FOC) and Direct Torque Control (DTC).Both methods have high dynamic performance in controlling PMSM. DTC method was first introduced for induction machines (IM) in 1980's [2-3], and then applied in PMSM recently [4]. DTC is attractive because of its simplicity, rapid response and high performance. In the DTC scheme, we keep the stator flux a constant value and then change the angle between the stator flux and the rotor flux so the torque can be changed at the same time. But there exist big ripples in torque, flux and current which have significant influence on the performance of controlling in the basic DTC scheme [5-6].To decrease the ripple Space Vector Pulse Width Modulation (SVPWM) method is introduced. Using this method, voltage space vectors applied to the inverter and their duration are calculated according to the error flux linkage vector, so that the error can be fully compensated. Besides the stator resistance changes with temperature variations and stator flux

This work was supported in part by the National High Technology Research and Development Program ("863") of China (SS2012AA052302) and in part by National Natural Science Foundation of China (No. 609704052, No. 61134001 and No. 51205046) estimation depends on the stator resistance .when the machine operate in a low speed great error will be exist between actual stator flux and the estimated stator flux. In order to overcome the drawbacks this paper presents an application of a PI FUZZY compensation method for the stator resistance variation based on errors between measured torque and the estimated torque. Compared with the basic DTC the FuzzyLogical-Based SVM-DTC reduce the ripples in torque and stator flux greatly, and make great improvement in dynamic performance of the control system.

\section{MODELING OF PMSM}

The PMSM equations in rotor reference frame $(d-q)$ are given as:

$u_{s d}=\frac{d \psi s d}{d t}+R i_{s d}-\omega \psi s q$

$u_{s q}=\frac{d \psi_{s q}}{d t}+R i_{s q}+\omega \psi_{s d}$

The equation of stator flux is

$\psi_{s d}=L_{s d} \dot{i}_{s d}+\psi f$

$\psi_{s q}=L_{s q} i_{s q}$

The equation of electromagnetic torque is :

$T_{e}=1.5 p\left(\psi_{s d} i_{s q}-\psi_{s q} i_{s d}\right)$

$T_{e}=T_{L}+(J / P) d \omega / d t$

Where $u_{s d}, u_{s q}, i_{s d}, i_{s q}, \psi_{s d}, \psi_{s q}$ are d-q voltages, current and stator flux respectively. $R$ is the stator resistance; $L_{s d}, L_{s q}$ are d-q axes inductions; $\psi_{f}$ is the flux linkage of the rotor. $P$ is the polar pair. $T_{e}$ is electromagnetic torque, $T_{L}$ is load moment, $J$ is moment of inertial. $\omega$ is the rotate speed. 


\section{BASIC DTC CONTROL}

The stator flux linkage vector $\psi_{s}$ and rotor flux linkage vector $\psi_{f}$ can be drawn in the rotor flux linkage e(d-q) and stator flux linkage(X-Y) reference frames as in Fig. 1[7]. $\delta$ is the angle between the stator and rotor flux linkage, In the steady state, $\delta$ is constant corresponding to a load torque and both stator and rotor flux linkage rotate at the synchronous speed. In transient operation, $\delta$ varies and the stator and rotor flux linkage rotate at different speeds. Since the electrical time-constant is normally much smaller than the mechanical time-constant, the rotating speed of stator flux linkage with respect to the rotor flux linkage can be easily changed.

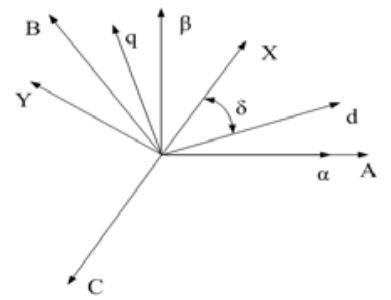

Figure 1. The Reference Frames Used in DTC

The electromagnetic torque equation can be expressed in $\mathrm{XY}$ reference frame in terms of the stator flux linkage and its angle with respect to rotor flux linkage as follows:

$$
\begin{aligned}
& T_{e}=\frac{3 p\left|\psi_{s}\right|}{4 L_{d} L_{q}}\left[2 \psi_{f} L_{q} \sin \delta-\left|\psi_{s}\right|\left(L_{q}-L_{d}\right) \sin 2 \delta\right] \\
& \frac{d T_{e}}{d t}=\frac{3 p\left|\psi_{s}\right|}{4 L_{d} L_{q}}\left[2 \psi_{f} L_{q} \cos \delta-2\left|\psi_{s}\right|\left(L_{q}-L_{d}\right) \cos 2 \delta\right] \frac{d \delta}{d t}
\end{aligned}
$$

For surface PMSM, $L_{d}=L_{q}$, (7) becomes:

$$
T_{e}=\frac{3 p\left|\psi_{s}\right|}{2 L_{d} L_{q}} \psi_{f} L_{q} \sin \delta
$$

From (10) we can know that the electromagnetic torque can be easily changed by changing the angle $\delta$ if we can keep the stator flux a constant value. The structure of the basic DTC is shown in Fig. 2.Stator flux linkage vector and torque are estimated and These estimated values are compared to reference values and the errors are applied to the hysteresis controllers. According to the hysteresis outputs, the estimated angle of flux linkage and a switching table, suitable voltage vectors are selected and applied to the inverter.

The estimation of torque and stator flux is derived from the following equations:

$$
\begin{aligned}
& \Psi_{\alpha}=\int\left(u_{\alpha}-R \dot{i}_{a}\right) d t+\Psi_{\alpha 0} \\
& \Psi_{\beta}=\int\left(u_{\beta}-R i_{\beta}\right) d t+\Psi_{\beta 0} \\
& \left|\psi_{s}\right|=\sqrt{\psi \alpha^{2}+\psi^{2}} \\
& \delta=\arctan \frac{\psi \alpha}{\psi \beta}
\end{aligned}
$$

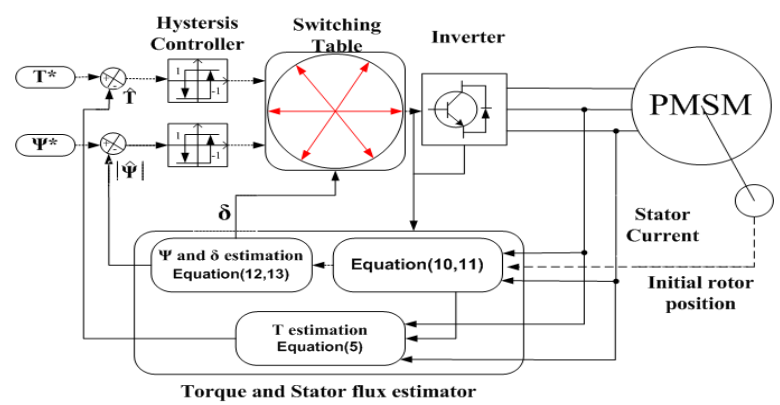

Figure 2. Diagram of Basic DTC

IV. IMPROVEMENT OF DTC

\section{A. Main Defect Of DTC}

1) In the basic DTC scheme, torque and flux are estimated and then regulated using two hysteresis controllers. The appropriate switching state for inverter is chosen according hysteresis outputs and a switching table.But it can not produce a perfect stator voltage to compensate the variation of the stator flux.So there exist big ripples in the stator flux and torque.

2) The stator resistance changes with temperature variations and stator flux estimation depends on the stator resistance. When the machine operate in a low speed great error will be exist between actual stator flux and the estimated stator flux.

\section{B. SVM-DTC to Reduce Ripple in Torque and Flux Linkage}

The application of DTC in PMSM needs to keep the amplitude of the stator flux a constant value. When the amplitude of the stator flux changed we can produce a perfect voltage to compensate the variation through the SVPWM method [8-10].

Stator flux model:

$u_{s}=\frac{d \psi_{s}}{d t}+R i_{s}$

discrete form:

$u_{s} * T_{s}=\psi_{s k+1}-\psi_{s k}+R i_{s k} T_{s}$

From (15) we can get the voltage that can compensate the variation of the stator flux completely. So we can produce the voltage by SVPWM in this way for example shown in Fig.3:

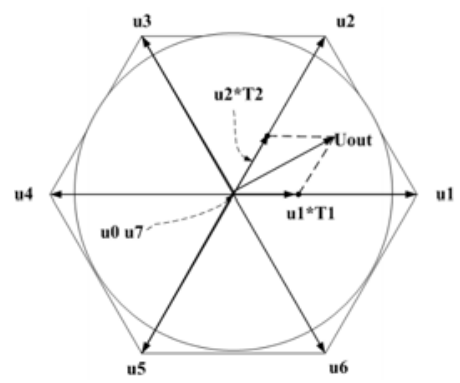

Figure 3. Voltage space vectors 


$$
u_{s} * T_{s}=\psi_{s k+1}-\psi_{s k}+R i_{s k} T_{s}=u_{1} * T_{1}+u_{2} * T_{2}
$$

Where $T s$ is Sampling time $T_{1}, T_{2}$ is duration of voltage vector $u_{1}, u_{2}$ respectively $u_{s}$ is the output voltage vector. $\psi_{s k}, \psi_{s k+1}$ is the stator flux in second $\mathrm{k}$ and $k+1$.

In the SVM-DTC method we use a PI controller and a reference flux vector calculator instead of hysteresis controller and the switching table [11]. First, the estimated torque is compared with the reference torque, which produces torque error. Reference flux vector is calculated with the torque error and reference flux. According to the error and the PMSM equations the voltage space vectors and their durations are selected and calculated so the stator flux error is fully compensated .

\section{PI_FUZZY Estimator for Stator Resistance}

Stator resistance will change when the temperature varies. In the DTC method, the estimated stator flux is used to calculate the stator flux and torque of PMSM .So when the stator resistance changes the estimated stator flux and the torque in the controller may be significantly different from the actual stator flux and torque of PMSM and thereby deteriorate the overall performance of the DTC system. So it is important to estimate the stator resistance during operation. We know that variation of the stator resistance will cause an error between the estimated torque and the actual torque. So we can predict the stator resistance via the difference between estimated torque and actual torque. In this paper we introduce a fuzzy logic based PI controller to predict the variation of the stator resistance. Fuzzy logic controller is a rule based controller where a set of rules are used to correct the effect of certain variation coming from the control system. In fuzzy logic, the error $(e)$ and error change rate $(e c)$ of the system output are two main input variables used in the Fuzzy system. Its control rule is basically composed by many IF-THEN statements shown as following:

\section{If $e$ is $A_{i}$ and $e c$ is $B_{j}$ then $\mathrm{u}$ is $u_{i j}$}

Where, $i$ and $j$ are the number indexes of control rules, $u$ is the output of fuzzy controller. The structure of the controller is shown in Fig. 4 and structure of Fuzzy-LogicalBased SVM-DTC is shown in Fig. 5.

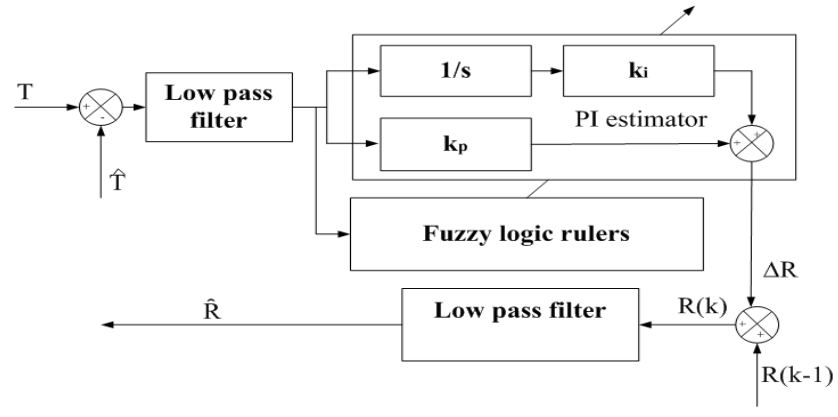

Figure 4. Fuzzy Logic Based Stator Resistance Estimator

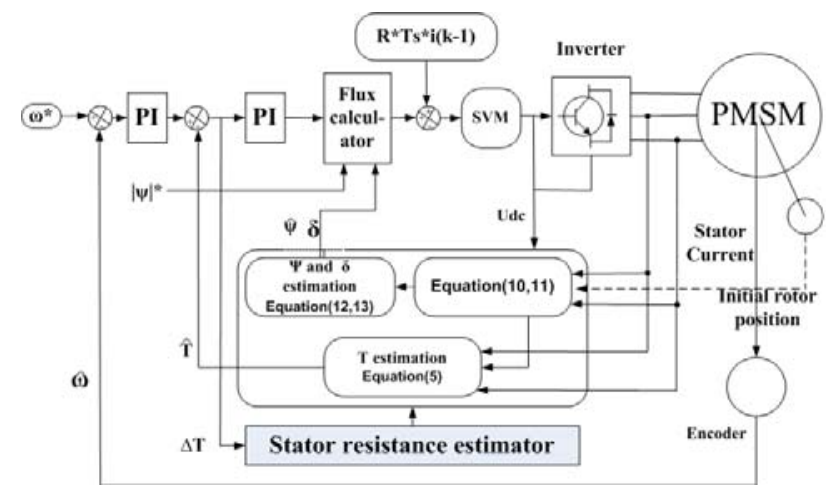

Figure 5. Diagram of Fuzzy-Logic-Based SVM-DTC

\section{Simulation AND RESUlts}

To examine the performance of the proposed fuzzy- logicbased SVM-DTC, two Matlab/Simulink models were compared. Parameters of the PMSM used in the paper are as follows:

$$
\begin{array}{ll}
\text { d-axis inductance } & L_{d}=3.03 \mathrm{mH} \\
\text { q-axis inductance } & L_{q}=3.03 \mathrm{mH} \\
\text { Stator resistance } & R=0.86 \mathrm{ohm} \\
\text { Rotor flux linkage } & \psi_{f}=0.0589 \mathrm{~Wb} \\
\text { Inertia constant } & J=0.00106 \mathrm{Nms} \\
\text { Number of pole pairs } & P=8
\end{array}
$$

Fig. 6 and Fig. 7 show the stator flux linkage of PMSM with basic DTC and Fuzzy-Logic-based SVM-DTC respectively. We can see great ripple exist in basic DTC and the proposed method in this paper reduce the ripple a lot. Fig.7 and Fig. 8 show the dynamic torque response of PMSM with basic DTC and Fuzzy-Logic-based SVM-DTC, from which we can see Fig.8 shows a more excellent system in dynamic performance. Also great ripple decreased in torque.

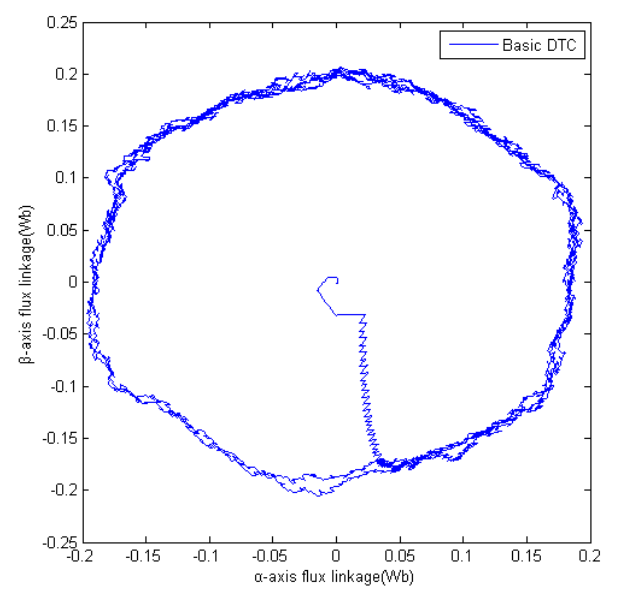

Figure 6. Stator flux linkage of Basic DTC 


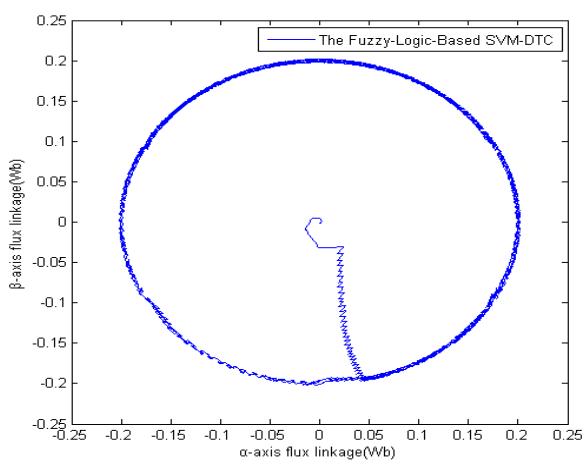

Figure 7. Stator flux linkage of Fuzzy-Logic-Based SVM-DTC

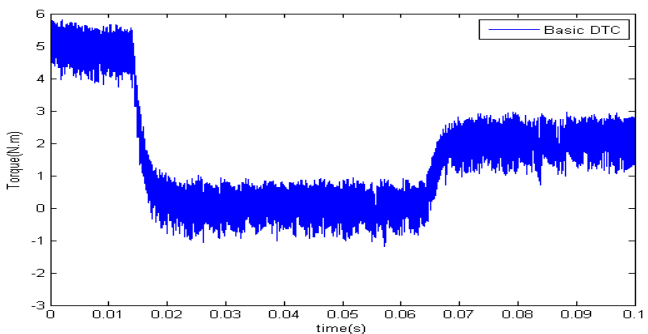

Figure8. Torque of Basic DTC

Fig. 10 shows when the stator resistance changed to 1.5 times its actual value at 0.035 second, the system without fuzzy controller becomes unsteady .In the paper we estimate the stator resistance through a fuzzy controller. Fig. 9 shows there has little influence on the system which use a fuzzy controller to estimate the stator resistance when the stator resistance changed at 0.035 second.

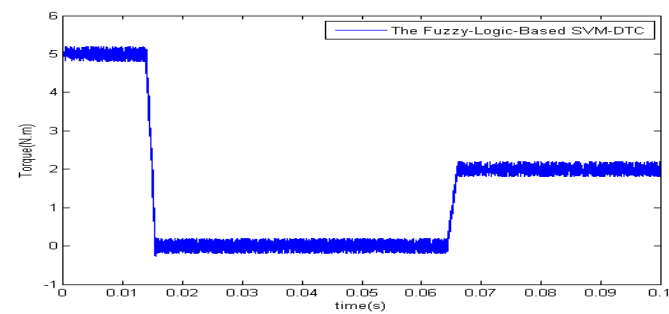

Figure 9. Torque of Fuzzy-Logic-Based SVM-DTC

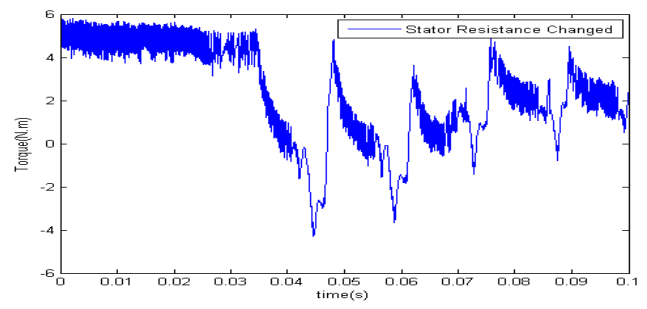

Figure 10. Simulation of Basic DTC when stator resistance changed

\section{CONCLUSION}

In this paper, a fuzzy logic based estimator for stator resistance is designed to predict the variation of the stator resistance. And in order to decrease the cripple in stator flux linkage and torque we use a SVM-DTC instead of the basic DTC. The simulation results show that the proposed method can estimate stator resistance and keep the estimated flux and torque with the reference value even in dynamic mode. This estimator is particularly effective at a low speed when the variation of resistance can not be neglected.

\section{REFERENCES}

[1] S. B. Ozturk, "Modeling, Simulation And Analysis Of Low-Cost Direct Torque Control Of PMSM Using Hall-Effect Sensors", Texas A\&M University, Dec. 2005.

[2] I. Takahashi and T. Naguchi, "A new quick-response and highefficiency control strategy of an induction motor," IEEE Trans. Ind. Applicant, vol. IA-22, pp. 820-827, Sept./Oct. 1986.

[3] L. Tang and M. F. Rahman, "A new direct torque control strategy for flux and torque ripple reduction for induction motors drive by space vector modulation," in Proc. IEEE PESC, Vancouver, BC, Canada, pp. 1440-1445, 2001.

[4] L. Tang, L. Zhong, M. F. Rahman and Y. Hu, "A Novel Direct Torque Control for Interior PMSM Drive With Low Ripple in Torque and FluxA Speed- Sensorless Approach", IEEE Trans. On Industry Application, Vol. 39, No. 6, pp 1748-1756, Dec. 2003.

[5] Mario Pacas,Jürgen Weber. Predictive Direct Torque Control for the PM Synchronous Machine[J]. IEEE Transactions on Industrial Electronics, 2005,52(5):1350-1356.

[6] Zhong. L, Rahman. M. F, Hu. W. Y. ve Lim, K. W.: Analysis of Direct Torque Control in Permanent Magnet Synchronous Motor Drives, IEEE Transactions on Power Electronics, Vol. 12, No. 3, pp.528-536,1997.

[7] Muhammed Fazlur Rahman, Md. Enamul Haque, Tang Lix-in,et al. Problems Associated with the Direct Torque Control of an Interior Permanent Magnet Synchronous Motor Drive and Their Remedies [J]. IEEE Tansactions on Industrial E-lectronics, 2004, 51(4):799-809.

[8] James N. Nash, “ Direct Torque Control, Induction Motor Vector Control Without an Encoder” , IEEE Industry Applications, vol. 33, No. 2, March/April 1997.

[9] U. Baader and M. Depenbrock, “Direct self-control (DSC) of inverterfed induction machine: A basis for speed control without speed measurement," IEEE Industry Applications, vol. 28, pp. 581-588, May/June, 1992.

[10] M. Depenbrock, “Direct self-control (DSC) of inverter-fed induction machine," IEEE Trans., Power Electronic., vol. 3, pp. 420-429, Oct. 1988.

[11] Tang. LX, Zhong L, Rahman MF (2004) A novel direct torque controlled interior permanent magnet synchronous machine drive with low ripple in flux and torque and fixed switching frequency. IEEE $\mathrm{T}$ Power Electronics, 19: 346-354. 